\title{
Estatística multivariada na qualidade da água residuária utilizadas na irrigação na região semiárida brasileira
}

O semiárido do nordeste brasileiro é caracterizado pelas irregularidades pluviométricas e altas temperaturas. Essas características se tornam um fator limitante para a produção agrícola da região, reduzindo a disponibilidade de água, sobretudo que atendam parâmetros ideais para a irrigação. Dessa forma, objetivou-se com este trabalho avaliar a estatística multivariada como ferramenta para analisar a qualidade de água residuária utilizada por agricultores na região semiárida. A coleta dos dados foi realizada em três cidades da região semiárida em dois períodos distintos. Foram realizadas análises laboratoriais dos parâmetros químicos, físicos e microbiológicos e sua classificação quanto à indicação para uso de água para irrigação. Realizou-se a análise de componentes principais para averiguar os parâmetros que exerceram maiores influencias na qualidade das águas nas cidades estudadas nos dois períodos e análise de agrupamento hierárquico para averiguar a familiaridade dos parâmetros. A qualidade da água superficial foi influenciada pelo local de sua proveniência, como as subterrâneas, que foram influenciadas pela composição química do solo e pela utilização de fossas ineficientes. A superficial foi influenciada, sobretudo por esgotos e pela poluição de indústrias e veículos. As águas também foram influenciadas pelo volume de precipitação, tendo uma menor qualidade quando se apresentou maior volume de chuva.

\section{Multivariate statistics on wastewater quality used in irrigation in the Brazilian semiarid region}

\begin{abstract}
The semiarid of northeastern Brazil is characterized by rainfall irregularities and high temperatures. These characteristics become a limiting factor for the region's agricultural production, reducing water availability, especially if they meet ideal parameters for irrigation. Thus, the objective of this study was to evaluate multivariate statistics as a tool to analyze the quality of wastewater used by farmers in the semiarid region. Data collection was performed in three cities of the semiarid region in two distinct periods. Laboratory analyzes of chemical, physical and microbiological parameters and their classification as to the indication for water use for irrigation were performed. Principal component analysis was performed to verify the parameters that had the greatest influence on water quality in the cities studied in both periods and hierarchical cluster analysis to verify the familiarity of the parameters. The quality of surface water was influenced by where it came from, such as groundwater, which was influenced by the chemical composition of the soil and the use of inefficient pits. The superficial was influenced mainly by sewers and pollution of industries and vehicles. The waters were also influenced by the volume of precipitation, having a lower quality when it presented larger volume of rain.
\end{abstract}

Keywords: Reuse; Statistical analysis; Microbiological; Heavy metals.

João Henrique de Andrade Cabral (i) Universidade Federal de Campina Grande, Brasil http://lattes.cnpq.br/3675200615907308 http://orcid.org/0000-0001-9158-0394 jandrade.cabral@gmail.com

Patrícia Ferreira da Silva (iD) Universidade Federal de Campina Grande, Brasil http://lattes.cnpq.br/8146309314429987 http://orcid.org/0000-0002-4580-2336 patrycyafs@yahoo.com.br

\section{Rigoberto Moreira de Matos (iD)}

Universidade Federal de Campina Grande, Brasil http://lattes.cnpq.br/9976807429777592 http://orcid.org/0000-0003-3455-9876 rigobertomoreira@gmail.com

DOI: 10.6008/CBPC2179-6858.2019.004.0010

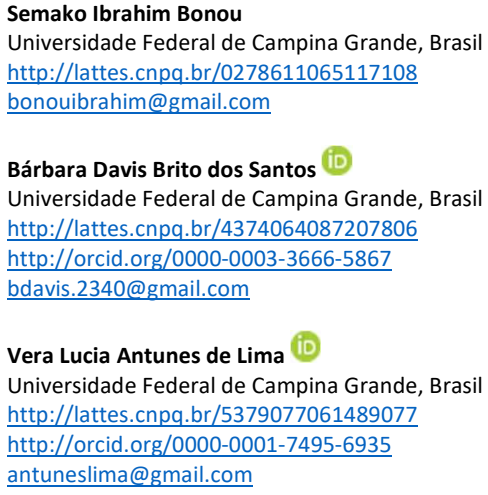

José Dantas Neto

Universidade Federal de Campina Grande, Brasi http://lattes.cnpq.br/9137226205129315 http://orcid.org/0000-0003-0798-6717 zedantas1955@gmail.com
Referencing this:

CABRAL, J. H. A.; SILVA, P. F.; MATOS, R. M.; BONOU, S. I.; SANTOS, B. D. B.; LIMA, V. L. A.; DANTAS NETO, J.. Estatística multivariada na qualidade da água residuária utilizadas na irrigação na região semiárida brasileira. Revista Ibero-Americana de Ciências Ambientais, v.10, n.4, p.121-133, 2019. DOI: http://doi.org/10.6008/CBPC21796858.2019 .004 .0010 


\section{INTRODUÇÃO}

As condições de escassez hídrica nas regiões semiáridas são influenciadas pela irregularidade das precipitações, consideradas um dos fatores que mais limitam a produção agrícola. Em função da reduzida disponibilidade de água de qualidade, o reuso de águas residuárias torna-se uma alternativa para a agricultura irrigada.

Nesse sentido, de acordo com Lemos et al. (2018), a aplicação gerenciada de água residuárias tratadas na agricultura irrigada tem vários benefícios sejam eles ambientais, incluindo a absorção e reciclagem de nutrientes do efluente, bem como o aumento da disponibilidade de água. O reúso tem se constituído em uma alternativa para diminuir a pressão de demanda sobre os mananciais, devendo ser inserido nos primeiros estágios do planejamento de recursos hídricos (URKIAGA et al., 2008; SCHAERBARBOSA et al., 2014). No entanto, Varallo et al. (2010) afirma que a água de reúso quando aplicada de forma inadequada podem causar danos às culturas agrícolas, propriedades físicas e químicas do solo, bem como ao meio ambiente. Já Pacheco et al. (2017) relata que o correto monitoramento dessas águas residuárias são necessários para avaliar seus efeitos sobre o meio ambiente como todo. Os parâmetros das qualidades das águas são regidos pela resolução no 357 do CONAMA (BRASIL, 2005). Esta resolução estabelece as classes de águas e os valores máximos permitidos (VMP) de substâncias químicas potencialmente prejudiciais, além de valores relativos a parâmetros físico-químicos e biológicos.

De acordo com Borges et al. (2018), esses parâmetros são fundamentais para determinação da qualidade da água seja para águas superficiais ou subterrâneas. A gestão dos recursos naturais é fundamental para preservar a água de qualidade para fins nobres, assim como auxiliar no desenvolvimento de técnicas alternativas para aproveitamento dos efluentes na agricultura, este que por sua vez são extremamente ricos em nutrientes minerais que podem ser assimilados pelas plantas. Deste modo, abordagens multivariadas, como Análise Fatorial (AF) e Análise de Componentes Principais (ACP), tem sido uma ferramenta utilizada com sucesso na gestão dos recursos hídricos (ZHANG et al., 2010).

De acordo com Guedes et al. (2012), a análise multivariada é amplamente utilizada quando se deseja promover a redução do número de variáveis com a menor perda de informações. A análise de componentes principais é um dos métodos de análise estatística mais utilizada para resolver problemas clássicos de análise fatorial, que por sua vez, permite a redução do número de variáveis facilitando a extração de informações que serão de grande relevância na avaliação da qualidade das águas e no manejo da bacia. Dada à relevância da temática, objetivou-se com este trabalho analisar a estatística multivariada com ferramenta para avaliar a qualidade de água residuária utilizada por agricultores na região semiárida.

\section{MATERIAIS E MÉTODOS}

\section{Localização da área de estudo}

O estudo foi conduzido nas cidades de Patos (PB), Santa Luzia (PB) e Santana do Seridó (RN), nos anos de 2017 e 2018. Inseridas na região semiárida brasileira e possuem as seguintes coordenadas geográficas, 
respectivamente: latitude $06^{\circ} 52^{\prime} 27^{\prime \prime} \mathrm{S}$, longitude $36^{\circ} 56^{\prime} 00^{\prime \prime}$ WGr, e altitude de $299 \mathrm{~m}$, na fazenda Poço Redondo; latitude $07^{\circ} 02^{\prime} 10,26^{\prime \prime}$ S e longitude $37^{\circ} 14^{\prime} 52,77^{\prime \prime}$ WGr, e altitude de $242 \mathrm{~m}$, no Sítio Felicidade. A cidade de Santana do Seridó está inserida no semiárido do estado do Rio Grande do Norte e possui a seguintes coordenadas geográficas: latitude: $6^{\circ} 45^{\prime} 58^{\prime \prime} \mathrm{S}$, longitude: $36^{\circ} 44^{\prime} 0^{\prime \prime} \mathrm{W}$, e uma altitude de $304 \mathrm{~m}$.

A principal característica dessas regiões não é a ausência de chuvas, mas sua irregularidade (RODRIGUES, 2002). A precipitação média é em torno de $500 \mathrm{~mm}$ com maior concentração nos meses de janeiro a maio. A temperatura média é em torno de $27,6^{\circ} \mathrm{C}$ com média máxima de $33,0^{\circ} \mathrm{C}$ e mínima de $22,3^{\circ} \mathrm{C}$, e a umidade relativa do ar oscila de 50 a $70 \%$.

\section{Condução do Estudo}

As coletas de águas residuárias nas cidades foram realizadas a cada dois meses, entre as $8 \mathrm{~h}$ e as $12 \mathrm{~h}$ e enviadas aos respectivos laboratórios para análises. As amostras foram acondicionadas em isopor e preservadas à temperatura de $0 \mathrm{a} 4^{\circ} \mathrm{C}$ até o momento da análise, realizada em laboratório. $\mathrm{O}$ monitoramento dos parâmetros físico-químicos das águas residuárias utilizadas na irrigação foi realizado a partir de amostras simples. Para o armazenamento das amostras foram utilizadas garrafas plásticas, com volume de $1000 \mathrm{ml}$, sendo previamente higienizadas com a própria água do local.

Após a coleta, os recipientes foram hermeticamente fechados, devidamente identificados e encaminhados para análise no Laboratório de Irrigação e Salinidade (LIS) da Universidade Federal de Campina Grande (UFCG), onde foram determinados: potencial de hidrogênio $(\mathrm{pH})$, condutividade elétrica da água (CEa), cálcio $\left(\mathrm{Ca}^{++}\right)$, magnésio $\left(\mathrm{Mg}^{++}\right)$, sódio $\left(\mathrm{Na}^{+}\right)$, potássio $\left(\mathrm{K}^{+}\right)$, bicarbonato $\left(\mathrm{HCO}_{3}^{-}\right)$, carbonato $\left(\mathrm{CO}_{3}{ }^{-}\right)$, cloreto (Cl-) e RAS, em conformidade com Richards (1954).

\section{Análises microbiológicas}

Para análise microbiológica foram coletadas amostras de água do ponto de emissão do sistema de irrigação, acondicionadas em recipientes apropriados, etiquetados e encaminhadas ao Laboratório de Referência em Dessalinização - LABDES/UFCG. Foram avaliados o número mais provável $\left(\mathrm{NMPg}^{-1}\right)$ de coliformes totais e termotolerantes $\left(45^{\circ} \mathrm{C}\right)$ determinados pela técnica dos tubos múltiplos em uma série de três tubos e posteriormente realizada o teste presuntivo e o confirmatório conforme metodologia proposta por Silva et al. (2010). Para a Escherichia coli foi utilizado o método American Public Health Association (APHA, 2005) do número mais provável. Para a preparação das amostras para as análises microbiológicas, foram tomadas por base orientações contidas na American Public Health Association (APHA), descritas na 4 ำ edição do Compendium of Methods for Microbiological Examination of Foods (DOWNES et al., 2001).

\section{Análise de metais pesados}

A determinação dos teores de metais pesados nos extratos das amostras de água, foi obtida usando espectrofotômetro de emissão ótica de plasma acoplado por indução (ICP-OES). Os metais pesados analisados foram: $\mathrm{Ni}, \mathrm{Pb}, \mathrm{Cd}, \mathrm{Cr}$ e Fe. Estes determinados no laboratório do Centro de Ciências Agrárias da 
Universidade Federal da Paraíba (UFPB) - Campus Areia (PB). Estes metais foram classificados com base nos valores máximos permissíveis (VMP) estabelecidos na resolução do CONAMA 357/2005.

\section{Análise estatística}

Os dados obtidos foram padronizados, de modo a tornar a média nula e variância unitária. A estrutura multivariada dos resultados foi avaliada por meio da Análise exploratória de Componentes Principais (ACP), condensando-se a quantidade de informação relevante contida no conjunto de dados originais em um menor número de dimensões, resultantes de combinações lineares das variáveis originais geradas a partir dos autovalores mais elevados na matriz de covariância (HAIR et al., 2009).

\section{RESULTADOS E DISCUSSÕES}

\section{Análise de componentes principais}

Para determinar os fatores que representam a variabilidade da qualidade da água, sem haver perda de informações, foi realizada a análise fatorial. A técnica de componente principal foi utilizada para a extração dos fatores. Considerando ainda o critério de Kaiser, no qual os autovalores dos fatores devem ser maiores que 1, foram obtidos cinco fatores (tabela 1) que explicam $100 \%$ da variação dos dados.

Tabela 1. Porcentagem de variação dos dados da análise de componentes principais.

\begin{tabular}{|c|c|c|}
\hline Componente Principal & \% de Variância & \% de Variância acumulada \\
\hline CP 1 & 73,23047 & 73,2305 \\
\hline CP 2 & 14,59818 & 97,8286 \\
\hline CP 3,5918 \\
\hline CP 4 & 5,76320 & 97,3494 \\
\hline CP 5 & 3,75750 & 100,0000 \\
\hline
\end{tabular}

Legenda: CP 1, Componente principal 1; CP 2, Componente principal 2; CP 3, Componente principal 3; CP 4, Componente principal 4; CP 5, Componente principal 5.

Da variação total dos dados foram extraídos os dois principais fatores, onde, 73,23\% da variação se deve a componente 1 (CP1) e 14,60\% a componente 2 (CP2), somados, ambos são responsáveis por 87,83\% da variação dos dados, além disso, levando em consideração o critério de Kaiser, ambos apresentaram autovalores superior a 1; logo, podemos reduzir os estudos a essas duas componentes. Estes resultados estão próximos aos obtidos por Zamberlan et al. (2013), onde os dois fatores principais explicam 92,14\% das variações dos dados originais de um total de dez fatores baseados nas variâncias calculadas. A partir da análise de componentes principais foi possível identificar as cargas fatoriais das duas componentes conforme a tabela 2 .

Tabela 2: Cargas de cada variável nas duas principais componentes.

\begin{tabular}{|c|c|c|}
\hline Parâmetros & CP1 & CP2 \\
\hline PH & $-0,94676$ & 0,062311 \\
\hline $\mathbf{C E}$ & 0,37637 & $-0,834415$ \\
\hline $\mathbf{C a}$ & $-0,96566$ & 0,212519 \\
\hline $\mathbf{M g}$ & $-0,94369$ & 0,284052 \\
\hline $\mathbf{N a}$ & $-0,95802$ & 0,239185 \\
\hline $\mathbf{K}$ & $-0,94890$ & 0,258454 \\
\hline Carbonatos & 0,48510 & 0,530031 \\
\hline Bicarbonatos & $-0,96531$ & 0,097118 \\
\hline Cloretos & $-0,96925$ & 0,226103 \\
\hline
\end{tabular}




\begin{tabular}{|c|c|c|}
\hline Coli. Totais & $-0,72925$ & 0,430749 \\
\hline Coli. coli & 0,18605 & 0,882830 \\
\hline $\mathbf{N i}$ & $-0,98240$ & 0,102624 \\
\hline $\mathbf{P b}$ & $-0,95305$ & 0,128758 \\
\hline $\mathbf{C d}$ & $-0,98240$ & 0,102624 \\
\hline $\mathbf{C r}$ & $-0,98240$ & 0,102624 \\
\hline
\end{tabular}

Legenda: $\mathrm{pH}$ - potencial hidrogeniônico; $\mathrm{CE}$ - condutividade elétrica; $\mathrm{Ca}$ - cálcio; $\mathrm{Mg}$ - magnésio; $\mathrm{Na}$ - sódio; $\mathrm{K}$ - potássio; Coli. Totais coliformes totais; Coli. Coli - Escherichia coli; $\mathrm{Ni}$ - níquel; $\mathrm{Pb}$ - chumbo; $\mathrm{Cd}$ - cádmio; $\mathrm{Cr}$ - cromo; e Fe - ferro.

Ao analisar o gráfico dos scores (figura 1A) observou-se que a componente principal CP1 separou as cidades entre os anos analisados. As cidades apresentaram score positivo para o ano de 2018 e negativo para o ano de 2017. Para a componente CP2, as cidades de Santa Luzia e Santana do Seridó no ano de 2017 e, Patos e Santa Luzia no ano de 2018 apresentaram scores negativo, já as cidades de Patos e Santana do Seridó, para os anos de 2017 e 2018, respectivamente, apresentaram score positivo.
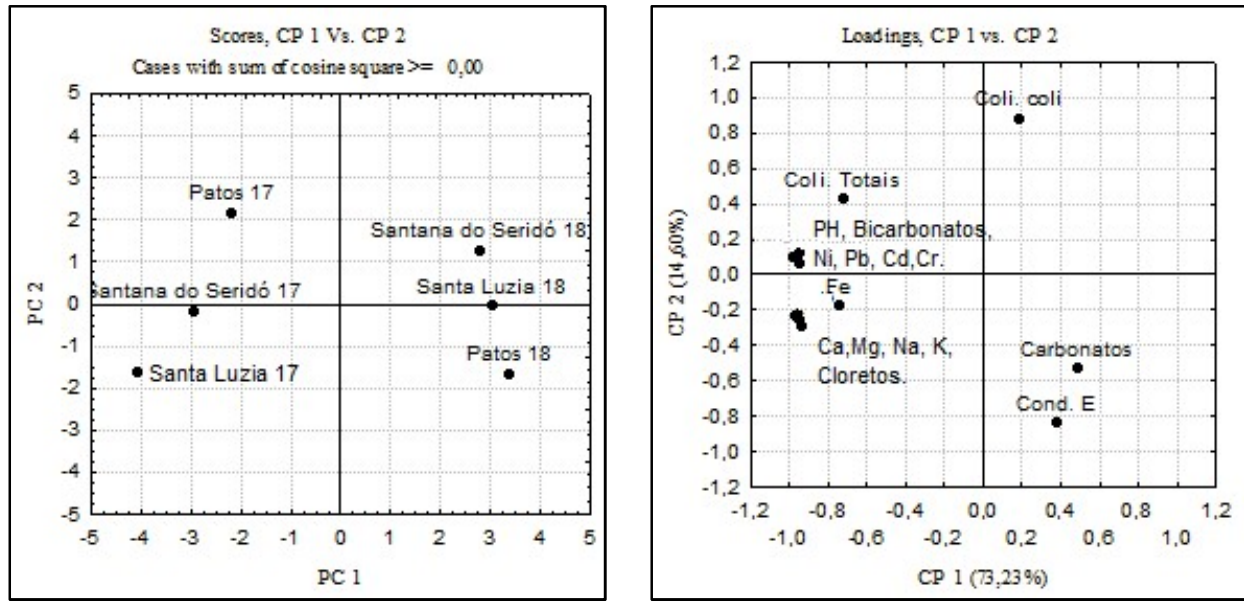

Figura 1: Gráficos dos scores: a) dos loadings; b) da CP1 versus CP2.

Analisando os gráficos dos loadings (figura 1B), percebe-se que a CP1 separou os componentes em dois grupos. O primeiro com valores negativos que apresentaram maiores cargas para essa componente e, formados pelas variáveis Coliformes totais, $\mathrm{PH}$, bicarbonatos, $\mathrm{Ni}, \mathrm{Pb}, \mathrm{Cd}, \mathrm{Cr}$, Ferro, $\mathrm{Ca}, \mathrm{Mg}, \mathrm{Na}, \mathrm{K}$ e Cloretos, que se relacionam negativamente com o segundo grupo. O segundo grupo com valores positivos, que apresenta menores cargas, é composto pelas variáveis Escherichia coli, Carbonatos e Condutividade Elétrica. Resultados semelhantes foram encontrados por Aguiar Neto et al. (2013) e Santana et al. (2016). Essas variáveis são importantes tanto para a qualidade da água de rios urbanos quanto para poços amazonas.

Essa divisão realizada pela CP1 pode ser explicada pela relação entre as variáveis de cargas maiores e menores, onde as que apresentaram cargas menores são dependes das demais que apresentaram cargas maiores. A correlação negativa entre o primeiro e o segundo grupo não corresponde necessariamente a algo antagônico entre as variáveis, mas, a uma relação de proximidade entre as variáveis do mesmo grupo. A condutividade elétrica, Escherichia coli. e carbonatos, tem uma relação de aumento ou diminuição com os sais, coliformes totais e metais pesados, todos presentes nas cargas maiores. A condutividade elétrica das águas relaciona-se com os sais dissolvidos nas águas, que podem estar relacionados às atividades agrícolas e industriais desenvolvidas próximas a estas fontes de água ou mesmo a características geológicas do material de origem dos solos. Sendo assim, as cargas menores foram atribuídas as variáveis dependentes. 
Analisando conjuntamente os scores e os loadings para a CP1, observou-se que as cidades nos anos de 2017 sofreram maiores influências pelas variáveis independentes. O ano de 2017 apresentou os menores valores de chuvas para a cidade de Santa Luzia (PB) e Santana do Seridó (RN) e maior valor de chuva para a cidade de Patos (PB), segundo informações AESA (2019) e EMPARN (2019) (figura 2).

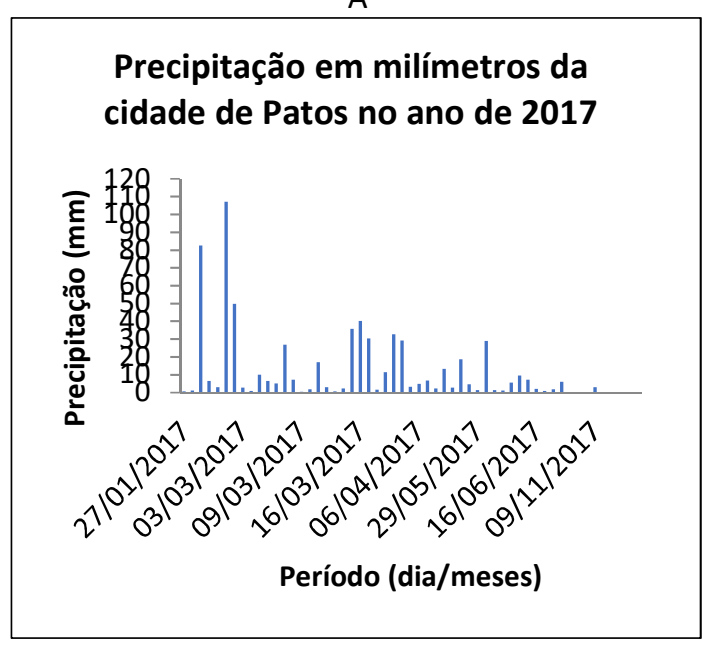

C

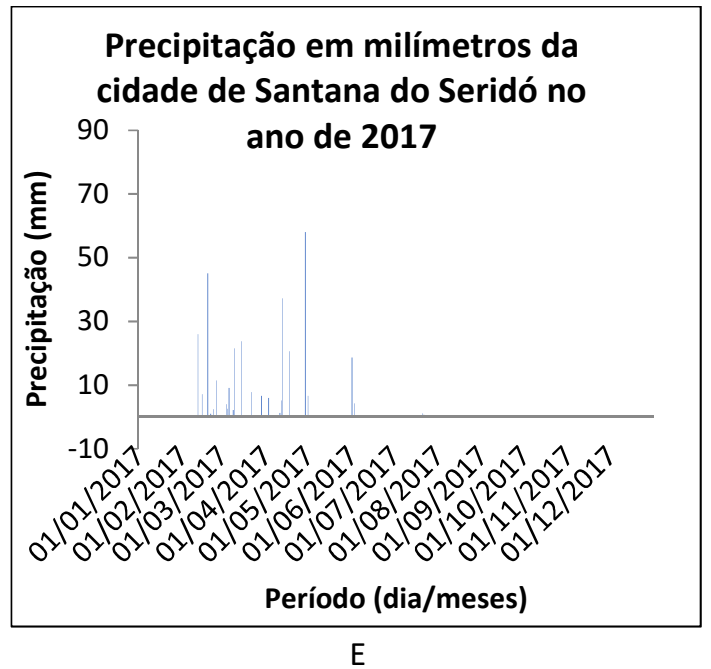

Precipitação em milímetros da cidade de Santa Luzia no ano de 2017

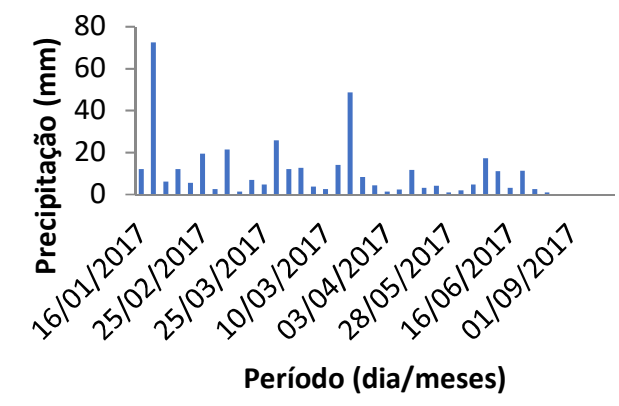

B
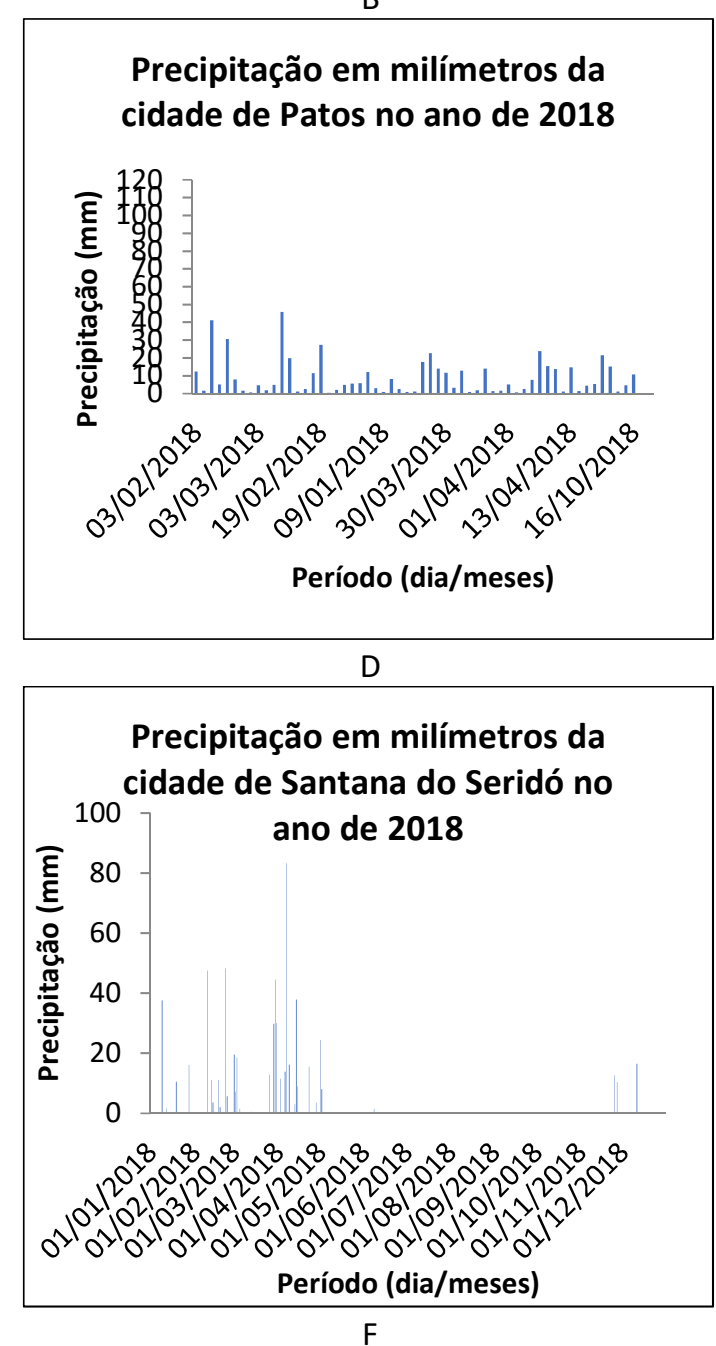

Precipitação em milímetros da cidade de Santa Luzia no ano de 2018

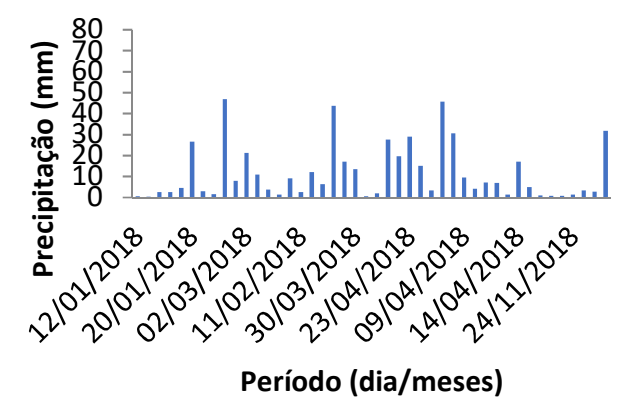

Figura 2: Médias mensais de precipitações para os anos de 2017 e 2018 para as cidades de Patos (PB) (A e B), Santana do Seridó (RN) (C e D) e Santa Luzia (PB) (E e F) dados obtidos da AESA e EMPARN.

Em contrapartida, as variáveis dependentes exerceram maior influência no ano de 2018, que apresentou maiores valores de chuva para as cidades Santa Luzia (PB) e Santana do Seridó (RN) e menor valor 
de chuva para a cidade de Patos (PB). O agrupamento da cidade de Patos (PB), em seu menor volume de chuva com as demais cidades em seus maiores, pode ser explicado pela origem de sua água, que provém do rio espinharas e tem sua origem entre as cidades de Salgadinho e Junco do Seridó. Em ambas as cidades houve um aumento das precipitações no ano de 2018 em relação ao ano de 2017, segundo a AESA (2019).

As águas coletadas nas cidades de Santa Luzia e Santana do Seridó têm origem de poços artesianos, assim, o aumento das precipitações e escoamento da água foi responsável pela lixiviação dos sais. $O$ aumento da precipitação nas cidades de Santa Luzia e Santana do Seridó e nas cidades de origem do rio espinharas, justificam a influência da condutividade elétrica, carbonatos e Escherichia coli. no ano de 2018. Com o aumento do volume de água, tanto na infiltração como no escoamento superficial reflete no carreamento de sais, microrganismos e carbonatos.

Santos et al. (2015) afirma que ocorre uma redução gradativa na qualidade da água no período chuvoso, quando comparado ao período de seca. Essa redução se dá em decorrência das elevadas concentrações de fósforo, sais solúveis e potássio. Sobretudo, o enquadramento das cidades em seus anos de maior volume de água com as variáveis dependentes, reforça ainda mais o resultado das cargas das variáveis independentes, onde estas exercem influências tanto em anos com menor volume de água, como em anos de maior volume de água, embora, em anos de maior volume de água, esses compostos estejam intrínsecos em outros compostos.

A CP2 que correspondeu por $14,60 \%$ das variações dos dados apresentou cargas de maior valor para duas variáveis, Escherichia coli. e Condutividade elétrica. A Escherichia coli. apresentou valor positivo, enquanto a condutividade valor negativo. As demais variáveis não apresentaram influência. Quanto às cidades, a CP2 as dividiu em dois grupos, onde o primeiro se encontra as cidades de Patos e Santana do Seridó, nos anos de 2017 e 2018, respectivamente. O segundo agrupou as demais cidades e anos. Analisando os dados meteorológicos fornecidos pela AESA (2019) e EMPARN (2019), constatou-se que ambas as cidades do primeiro grupo apresentaram volumes de precipitações muito semelhantes, pouco mais de $630 \mathrm{~mm}$.

O primeiro grupo sofreu maior influência da Escherichia Coli., sendo um indício da descarga de esgotos no rio espinharas, na cidade de Patos (PB) e da utilização de fossa negra na cidade de Santana do Seridó - RN, onde os dejetos são inseridos diretamente em contato com o solo. Resultado condizente ao constatado por Palacio et al. (2009), ao estudar a similaridade da qualidade das águas superficiais da bacia do Curu (CE).

O segundo grupo formado pelas cidades que apresentaram menor volume de precipitação sofreram maior influência da condutividade elétrica, que pode estar associado às atividades desenvolvidas próximas as estas fontes de água ou mesmo a características geológicas do material de origem dos solos. Quanto maior essa concentração de sais, maior a condutividade elétrica da água; logo, observa-se que os anos que apresentaram precipitação menor, obtiveram menos carga d'água e consequentemente a concentração de sais ficou maior.

Além disso, a Escherichia Coli. é uma variável dependente da condutividade elétrica pois necessita de um ambiente ideal. Logo, elas apresentam correlação negativa na CP2, e influenciando anos antagônicos 
aos volumes de chuva, sendo a Escherichia Coli. em anos onde a condutividade elétrica e concentração de sais esteja menor, neste caso, maior volume de chuva e diluição deles e condutividade elétrica em anos de menores volumes de chuvas e consequente aumento na concentração de sais.

Farias et al. (2010), estudando condições microbiológicas de tagelus plebeios em água no estuário do Rio Ceará, em Fortaleza (CE), constatou que em períodos de chuvas intensas, o fluxo de efluentes despejados na água é maior, resultando em um maior aporte de água doce no rio, com uma consequente diminuição da salinidade, associada a uma maior contaminação bacteriológica. Esses fatos corroboram com os resultados obtidos no presente estudo.

A semelhança entre as cidades e os anos de coleta foi avaliada pelo emprego da técnica de análise multivariada de agrupamento, onde formou dois grupos homogêneos (figura 3). Observou-se que as cidades foram separadas novamente entre os anos 2017 e 2018, assim como ocorreu na componente primária, evidenciando novamente o agrupamento das cidades em anos de maior volume de água.

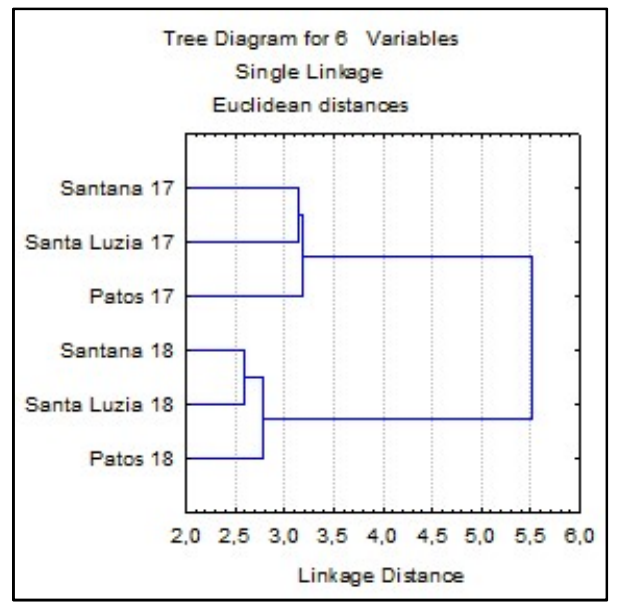

Figura 3: Dendograma indicando a similaridade entre as cidades e os anos estudados.

Essas informações corroboram com a análise de componente principal, que agrupou as cidades conforme os anos estudados. A familiaridade entre as cidades de Santana do Seridó (RN) e Santa Luzia (PB), demonstra a semelhança entre as águas analisadas, de onde ambas as águas provém de poço artesiano, diferentemente de patos, mostrando uma proximidade da composição química e física de águas subterrâneas. A semelhança entre as variaveis de qualidade da água analisadas em forma de um dendograma hierarquizado encontra-se na (figura 4). Houve maior similaridade entre $\mathrm{Mg}, \mathrm{K}, \mathrm{Na}$ e Ca. Esse tipo de agrupamento é esperado por todos serem minerais presentes em grande abundância na natureza e nas rochas originárias dos solos locais.

Cabe ainda ressaltar que a junção da condutividade elétrica com carbonatos, este que por sua vez são sais inorgânicos e exerce influência a capacidade de condução elétrica da água (figura 4). Tanto a consutividade elétrica, quanto os carbonatos, apresentam semelhança ao dependerem das outras variáveis, como os sais e os metais pesados, isso explica a junção de ambos e a distância da ligação com os demais, que apesar da dependência, há a necessidade de ligação de todos os outros anteriormente, principalmente para os carbonatos que precisa da junção de sais e metais. A proximidade existente entre bicarbonatos e alguns 
metais pesados, está relacionada a baixa concentração desses compostos nas águas analisadas. A correlação desse grupo com o pH das águas pode ser explicada devido à alcalinidade desses compostos, em especial o bicarbonato.

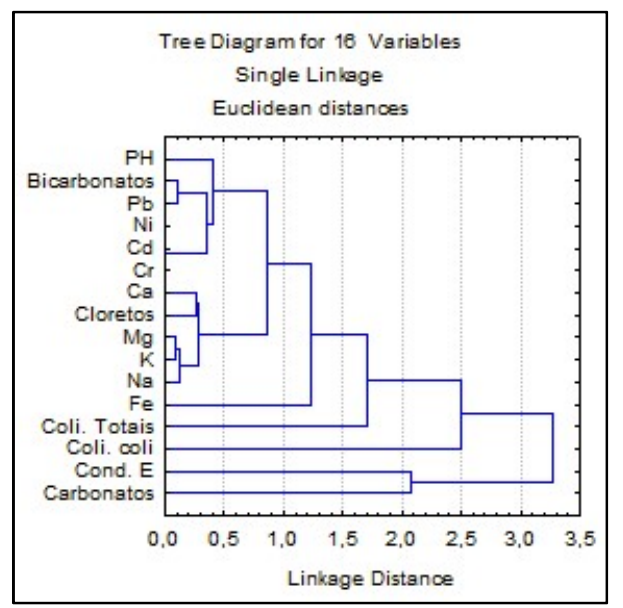

Figura 4: Dendograma da similaridade entre as variáveis do estudo.

\section{Análises Laboratoriais}

Quanto aos dados da análise da qualidade de água obtidos em laboratórios (tabela 3), utilizou-se a classificação de qualidade de água fornecida por Almeida (2010), e notou-se que, com exceção da cidade de Patos, no ano de 2017, as cidades apresentaram condutividade elétrica superior à recomendada para a agricultura, acima de $3 \mathrm{dS} \mathrm{m}^{-1}$. No entanto, a mesma cidade apresentou a maior condutividade elétrica no ano seguinte. Observou-se também que as menores condutividades elétricas foram obtidas nos anos de maior volume de chuva para as cidades de Santa Luzia e Patos. Almeida (2010) afirma ainda que, outros parâmetros têm influência na qualidade físico-químico da água, como por exemplo, a temperatura. O que pode explicar o que ocorreu em Santana do Seridó.

Tabela 3: Resultados físico-químicos obtidos em laboratórios.

\begin{tabular}{|c|c|c|c|c|c|c|c|c|}
\hline Local & $\begin{array}{c}\text { PH } \\
\left(\mathrm{meq} \mathrm{L}^{-1}\right)\end{array}$ & $\begin{array}{c}\text { CE } \\
\left(\mathrm{dS} \mathrm{m}^{-1}\right)\end{array}$ & $\begin{array}{c}\text { Ca } \\
\left(\text { meq L }^{-1}\right)\end{array}$ & $\begin{array}{c}\mathbf{M g} \\
\left(\mathrm{meq} \mathrm{L}^{-1}\right)\end{array}$ & $\begin{array}{c}\mathrm{Na} \\
\left(\mathrm{meq} \mathrm{L}^{-1}\right)\end{array}$ & $\begin{array}{c}\mathbf{k} \\
\left(\mathrm{mg} \mathrm{L}^{-1}\right)\end{array}$ & $\begin{array}{c}\mathrm{CO}_{3} \\
\left(\mathrm{meq} \mathrm{L}^{-1}\right)\end{array}$ & $\begin{array}{c}\mathrm{HCO}_{3} \\
\left(\mathrm{meq} \mathrm{L}^{-1}\right)\end{array}$ \\
\hline Santa L./17 & 7,89 & 4,627 & 86 & 85,68 & 697,82 & 73,32 & 0 & 606,95 \\
\hline Santa L./18 & 7,32 & 3,96 & 2,26 & 1,14 & 19,54 & 1,37 & 0 & 13,3 \\
\hline Patos/17 & 7,95 & 2,413 & 40,4 & 32,16 & 316,94 & 29,25 & 0 & 622,2 \\
\hline Patos/18 & 7,46 & 5,107 & 2,6 & 1,98 & 25,49 & 0,37 & 0,74 & 11,01 \\
\hline Santa do S./17 & 7,89 & 3,792 & 77,4 & 53,64 & 422,74 & 44,07 & 0 & 765,55 \\
\hline Santa do S./18 & 7,32 & 4,292 & 1,54 & 2,15 & 14,44 & 1,54 & 0 & 13,84 \\
\hline Média & 7,64 & 4,03 & 35,03 & 29,46 & 249,50 & 24,99 & 0,12 & 338,81 \\
\hline Desvio Padrão & 0,303 & 0,923 & 39,164 & 34,801 & 280,666 & 29,772 & 0,302 & 361,478 \\
\hline
\end{tabular}

Legenda: Santa L. - Santa Luzia; Santana do S. - Santana do Seridó; CE - condutividade elétrica; Ca - cálcio, Mg - magnésio, Na sódio; $\mathrm{K}$ - potássio, $\mathrm{CO}_{3}$ - carbonatos; e $\mathrm{HCO}_{3}$ - bicarbonatos.

Apesar disso, embora em anos contrários as águas subterrâneas das cidades de Santa Luzia e Santana do Seridó apresentaram condutividade elétrica parecidas, diferentemente da água coletada na cidade de Patos, de fonte superficial. Portanto, a formação geológica das rochas dos solos apresenta forte influência na composição e qualidade da água. Esses dados estão de acordo com os encontrados por Andrade Júnior et al. (2006), que constatou que a água encontrada no embasamento cristalino apresentou condutividade elétrica acima de $3 \mathrm{dS} \mathrm{m}^{-1}$, inviabilizando seu uso na irrigação. A análise laboratorial das águas apresentou a classificação da água para irrigação, segundo Richards (1954), onde foram classificadas em C4 no ano de 
2018, sendo uma água de salinidade muito alta e não apropriada para irrigação devido ao risco de salinização do solo.

Os valores de sódio estão dentro dos limites estabelecidos $\left(0-40 \mathrm{mql} \mathrm{L}^{-1}\right)$ para os anos de $2018 \mathrm{em}$ todas as cidades. No ano de 2017, observou-se valores extremamente altos, principalmente para as águas subterrâneas. $O$ ano de 2018 apresentou maiores índices de chuvas para as cidades de Santa Luzia, Santana do Seridó e as cidades de origem do rio espinharam. Embora o aumento da chuva possa ocasionar uma redução na qualidade da água carreando sais e minerais presentes no solo, também pode ocorrer à diluição das águas em seus reservatórios e, assim, diluir os sais presentes.

A concentração de cálcio e magnésio apresenta a mesma característica do sódio, onde se observou uma menor concentração e possível uso na agricultura no ano de maior volume de chuva. Já no ano de 2017, as concentrações foram superiores ao limite indicado. No entanto, Andrade Júnior et al. (2006) afirmou que a elevada concentração de cálcio + magnésio minimiza o efeito da concentração de sódio no aspecto de sodificação do solo. Portanto, embora no ano de 2017, ano de menor volume de chuva, apresentou maior concentração de sódio, também apresentou maior concentração de cálcio + magnésio, minimizando o efeito de sodificação.

Os carbonatos $\left(\mathrm{CO}_{3}\right)$ estão dentro do limite recomendado $\left(0\right.$ - $\left.0.1 \mathrm{meq} \mathrm{L}^{-1}\right)$, com exceção da cidade de Patos no ano de 2018. Para os bicarbonatos $\left(\mathrm{HCO}_{3}\right)$ constatou-se que todos estão acima do limite indicado (0 - 10 meq L-1), havendo uma grande elevação no ano de 2017 em relação ao limite superior. Quanto ao potássio $\mathrm{K}$, observou-se que os valores obtidos estão dentro do limite $\left(0-2 \mathrm{mg} \mathrm{L}^{-1}\right)$ no ano de 2018 . Por outro lado, os valores estão acima do limite permitido no ano de 2017, apresentando maiores valores para as águas subterrâneas.

Os valores obtidos nas análises da água para o potencial Hidrogeniônico estão dentro dos limites indicado $(6-8,5)$, conforme tabela 3. Ainda de acordo com a classificação de Almeida (2010), observou-se que os metais pesados (tabela 4) estão dentro dos limites estabelecidos para a agricultura em todas as cidades e em ambos os anos, com exceção da cidade de Santa Luzia no ano de 2017 que apresentou valor superior ao limite estabelecido para o ferro $\left(0-5 \mathrm{mg} \mathrm{L}^{-1}\right)$.

Tabela 4. Resultados biológicos e químicos obtidos em laboratórios.

\begin{tabular}{|c|c|c|c|c|c|c|c|}
\hline Local/Ano & Coli. Totais (ufc) & Coli. Coli (ufc) & $\begin{array}{c}\text { Ní } \\
\left(\mathrm{mg} \mathrm{L}^{-1}\right)\end{array}$ & $\begin{array}{c}\mathbf{P b} \\
\left(\mathrm{mg} \mathrm{L}^{-1}\right)\end{array}$ & $\begin{array}{c}\text { Cd } \\
\left(\mathrm{mg} \mathrm{L}^{-1}\right)\end{array}$ & $\begin{array}{c}\mathrm{Cr} \\
\left(\mathrm{mg} \mathrm{L}^{-1}\right)\end{array}$ & $\begin{array}{c}\mathrm{Fe} \\
\left(\mathrm{mg} \mathrm{L}^{-1}\right)\end{array}$ \\
\hline Santa L./17 & 10110 & 146 & 0,0001 & 1,694 & 0,0001 & 0,0001 & 9,639 \\
\hline Santa L./18 & 2020 & 2020 & 0 & 0 & 0 & 0 & 0 \\
\hline Patos/17 & 10110 & 10110 & 0,0001 & 1,895 & 0,0001 & 0,0001 & 4,6374 \\
\hline Patos/18 & 2020 & 1260 & 0 & 0 & 0 & 0 & 0 \\
\hline Santa do S./17 & 10110 & 146 & 0,0001 & 2,293 & 0,0001 & 0,0001 & 0,4256 \\
\hline Santa do S./18 & 10100 & 10100 & 0 & 0 & 0 & 0 & 0 \\
\hline Média & 7411,67 & 3963,67 & 0,00 & 0,98 & 0,00 & 0,00 & 2,45 \\
\hline Desvio Padrão & 4176,369 & 4809,757 & 0,000 & 1,091 & 0,000 & 0,000 & 3,964 \\
\hline
\end{tabular}

Legenda: Santa L. - Santa Luzia; Santana do S. - Santana do Seridó; Coli. Totais - coliformes totais; Coli. Coli - escherichia coli; Ni níquel, $\mathrm{Pb}$ - chumbo; $\mathrm{Cd}$ - cádmio; $\mathrm{Cr}$ - cromo, Fe - ferro.

Com exceção das cidades de Santa Luzia e Santana do Seridó, ambas no ano de 2017 para a Escherichia Coli., todas as amostras analisadas apresentaram valores superiores aos indicados pela resolução no 357 do CONAMA (BRASIL, 2005) para os coliformes. Demonstrando que com o aumento do volume de 
chuva, há uma tendência de carreamento desses microrganismos, principalmente de dejetos humanos. O rigoroso controle de coliformes e atividades agrícolas torna as águas analisadas fora do padrão para utilização na produção de alimentos.

Portanto, como identificado na análise de componentes principais, componente principal 1, para todas as cidades no ano de 2018, este de maior volume de chuva (figura 2), observou-se que as variáveis coliformes totais e condutividade elétrica apresentaram maior influência, ambos em valores superiores aos limites estabelecidos, o que explica tal influência. Além disso, o ato do maior volume de chuva pode explicar o carreamento de sais e microrganismos. A componente principal 1, também enquadrou as cidades no ano de 2017 com as demais variáveis. 0 ano de 2017 apresentou menor volume de chuva (figura 2), e, portanto, foi influenciado pelos sais e minerais, estes que por sua vez apresentaram valores superior aos limites permitidos.

A componente principal 2, embora tenha menor variação dos dados, dividiu em dois grupos, onde o primeiro encontra-se as cidades de Patos e Santana do Seridó, nos anos de 2017 e 2018, respectivamente. 0 segundo agrupou as demais cidades e anos. O primeiro grupo sofreu influência da Escherichia Coli., onde foram constatados, com a discussão sobre qualidade, que ambas as cidades apresentaram valores elevados de Escherichia Coli., estando fora do padrão estabelecido. Além disso, ambas apresentaram volumes de chuva semelhados, pouco mais de $630 \mathrm{~mm}$.

O segundo juntou as demais cidades e anos e sofreu influência da condutividade elétrica. Constatouse que essa condutividade elétrica das cidades desse grupo foi próxima ou superior a $4 \mathrm{dS} \mathrm{m}^{-1}$, sendo assim, classificadas em água de salinidade muito alta e não apropriada para irrigação de culturas agrícolas, de acordo com Richards (1954), esse fator pode explicar a influência dessa variável nas cidades e anos analisados.

\section{CONCLUSÃO}

A análise fatorial/análise de componentes principais permitiu a seleção de dois componentes indicadores da qualidade das águas nas três cidades nos dois anos, explicando 87,8\% da variância total. As variações na qualidade da água nas três cidades foram definidas por um grupo de nutrientes (influência da poluição difusa e da composição mineral das rochas que dão origem ao solo da região) e por um grupo orgânico (indicativo de lançamento de esgotos domésticos in natura no curso de água).

As variáveis 'condutividade elétrica', 'Escherichia coli.' e 'carbonatos' têm uma relação de dependência com os sais, coliformes totais e metais pesados, e assim, para exercerem influência nas águas, necessitam de sua variação que estão atrelados aos matérias de origem do solo, atividades agrícolas e industriais exercidas na região.

As águas de Santa Luzia e Santana do Seridó apresentaram maiores semelhanças em suas características devido ao fato de ambas serem proveniente do subsolo. Em contrapartida, o fato de Patos ser uma cidade mais desenvolvida, algumas características se sobressaíram, como a presença maior de metais 
pesado. As águas analisadas apresentaram índices superiores aos limites para coliformes e condutividade elétrica, devendo-se maior atenção em seu uso na irrigação.

\section{REFERÊNCIAS}

AESA. Agência Executiva de Gestão das Águas.

Meteorologia: Chuvas: Precipitação dos municípios.

Bodocongó: AESA, 2019.

AGUIAR NETTO, A. O.; GARCIA, C. A. B.; HORA ALVES, J. P.; FERREIRA, R. A.; SILVA, M. G.. Physical and chemical characteristics of water from the hydrographic basin of the Poxim River. Environmental Monitoring and Assessment, Aracaju, v.185, n.5, p.4417-4426, 2013.

ALMEIDA, O. Á.. Qualidade da água de irrigação. Cruz das Almas: EMBRAPA, 2010.

ANDRADE JÚNIOR, A. S.; SILVA, E. F. F.; BASTOS, E. A.; MELO F. B.; LEAL, C. M.. Uso e qualidade da água subterrânea para irrigação no semi-árido piauiense. Revista Brasileira de Engenharia Agrícola e Ambiental, v.10, n.4, p.873-880, 2006. http://doi.org/10.1590/S1415-43662006000400014

APHA. American Public Health Association. Standard methods for the examination of water and wastewater. Washington: APHA, 2005.

BORGES, S. A.; CUNHA A. H. N.; SILVA, S. M. C.; VIEIRA, J. A.; NASCIMENTO, A. D. R.. Qualidade da água de irrigação na cultura do tomate de mesa no município de GoianápolisGO. Multi-Science Journal, v.1, n.2, p.74-82, 2018. DOI: http://doi.org/10.33837/msj.v1i2.63

BRASIL. Resolução CONAMA 357 de 17 de março de 2005 Brasília: CONAMA, 2005.

DOWNES, F. P.; ITO, K.. Compendium of methods for the microbiological examination of foods. Washington: APHA, 2001.

EMPARN. Empresa de Pesquisa Agropecuária do Rio Grande do Norte. Meteorologia: Chuvas observadas no RN: Monitoramento pluviométrico. Parnamirim: EMPARN, 2019.

FARIAS, M. F.; ROCHA-BARREIRA, C. A.; CARVALHO, F. C. T.; SILVA, C. M.; REIS, E. M. F.; COSTA, R. A.; VIEIRA, R. H. S. F.. Condições microbiológicas de tagelus plebeius (lightfoot, 1786) (mollusca: bivalvia: solecurtidae) e da água no estuário do Rio Ceará, em Fortaleza-CE. Boletim do Instituto de Pesca, v.36, n.2, p.135-142, 2010 DOI: http://doi.org/10.2312/Actafish.2015.3.2.49-60

GUEDES, H. A. S.; SILVA, D. D.; ELESBON, A. A. A.; RIBEIRO, C. B. M.; MATOS, A. T.; SOARES, J. H. P.. Aplicação da análise estatística multivariada no estudo da qualidade da água do Rio Pomba, MG. Revista Brasileira de Engenharia Agrícola e Ambiental, v.16, n.5, p.558-563, 2012. DOI: http://doi.org/10.1590/S1415-43662012000500012

HAIR, J. F.; ANDERSON, R. E.; TATHAM, R. L.; BLACK, W. C.. Análise Multivariada de Dados. Porto Alegre: Bookman, 2009.
LEMOS, M.; FERREIRA NETO, M.; MEDEIROS, J. F.; DIAS, N. S; FRANÇA, Ê. F.; LIRA, R. B.. Avaliação nutricional da palma forrageira fertirrigada com efluente de esgoto doméstico. Caatinga, v.31, n.2, p.476-486, 2011. DOI: http://doi.org/10.1590/1983-21252018v31n224rc

PACHECO, F. P.; NÓBREGA, L. H. P.; TONINI, M.; SPIASSI, A.; ROSA, D. M.; CRUZ-ILVA, C. T. D. A.. Atributos físicos do solo após aplicação de água residuária de suinocultura aplicada em cobertura na cultura do milho e cultivo sequencial de aveia preta. Caatinga, v.30, n.4, p.955-962, 2017. DOI: http://doi.org/10.1590/1983-21252017v30n416rc

PALACIO, H. A. Q.; ANDRADE, E. M.; LOPES, F. B.; ALENXANDRE, D. M. B.; ARRAES, F. D. D.. Similaridade da qualidade das águas superficiais da bacia do Curu, Ceará. Ciência Rural, v.39, n.9, p.2494-2500, 2009. DOI: http://doi.org/10.1590/\$0103-84782009000900017

RICHARDS, L. A.. Diagnosis and improviment of saline and alkali soils. Washington: USDA, 1954.

RODRIGUES, J. L.. Atlas Escolar Paraíba. João Pessoa: Grafset, 2002.

SANTANA, N. R. F.; NETO, A. O. A.; SILVA, M. G.; GARCIA, C. A. B.. Índice de qualidade da água nas nascentes do Rio Piauitinga-SE por análise multivariada e o uso na irrigação. Revista Brasileira de Agricultura Irrigada, v.10, n.6, p.999-1010, 2016. DOI: http://doi.org/10.7127/rbai.v10n600441

SANTOS, E. A.; MARTINS, I.; SOUSA, J.; MENDES, A.; SILVA, P. D. S.. Qualidade da água no Lago de Sobradinho, BA: análise de componentes principais. In: JORNADA DE INICIAÇÃO CIENTÍFICA DA EMBRAPA SEMIÁRIDO, 10. Anais. Petrolina: EMBRAPA, 2015.

SHAER-BARBOSA, M.; SANTOS, M. E. P.; MEDEIROS, Y. D. P. Viabilidade do reúso de água como elemento mitigador dos efeitos da seca no semiárido da Bahia. Ambiente e Sociedade, v.17, n.2, p.17-32, 2014. DOI: http://doi.org/10.1590/S1414-753X2014000200003

SILVA, N.; JUNQUEIRA, V. C. A.; SILVEIRA, N. F. A.; TANIWAKI, M. H.; SANTOS, R. F. S.; GOMES, R. A. R.. Manual de métodos de análise microbiológica de alimentos e água. São Paulo: Varela, 2010.

URKIAGA, A.; FUENTES, L. L.; BIS, B.; CHIRU, E.; BALASZ, B. HERNÁNDEZ, F.. Development of analysis tools for social, economic and ecological effects of water reuse. Desalination, v.218, n.5, p.81-91, 2008. DOI: https://doi.org/10.1016/j.desal.2006.08.023

VARALLO, A. C. T.; CARVALHO, L.; SANTORO, B. L.; SOUZA, C F.. Alterações nos atributos de um Latossolo Vermelho amarelo irrigado com água de reuso. Revista Brasileira de Engenharia Agrícola e Ambiental, Campina Grande, v.14, 
n.4, p.372-377 2010. DOI: http://doi.org/10.1590/S141543662010000400005

ZAMBERLAN, J. F.; ROBAINA, A. D.; PEITER, M. X.; FERRAZ, R. C.; PINTO, L. M.. Índices sazonais de qualidade da água de irrigação via análise multivariada na região central do Rio Grande do Sul. Irriga, v.18, n.3, p.376-386, 2013. DOI: https://doi.org/10.15809/irriga.2013v18n3p376
ZHANG, X.; WANG, Q.; LIU, Y.; WU, J.; YU, M.. Application of multivariate statistical techniques in the assessment of waterquality in the Southwest New Territories and Kowloon, HongKong. Environmental Monitoring and Assessment, v.173, p.17-27, 2010. DOI: https://doi.org/10.1007/s10661010-1366-y

A CBPC - Companhia Brasileira de Produção Científica (CNPJ: 11.221.422/0001-03) detém os direitos materiais desta publicação. Os direitos referem-se à publicação do trabalho em qualquer parte do mundo, incluindo os direitos às renovações, expansões e disseminações da contribuição, bem como outros direitos subsidiários. Todos os trabalhos publicados eletronicamente poderão posteriormente ser publicados em coletâneas impressas sob coordenação da Sustenere Publishing, da Companhia Brasileira de Produção Científica e seus parceiros autorizados. Os (as) autores (as) preservam os direitos autorais, mas não têm permissão para a publicação da contribuição em outro meio, impresso ou digital, em português ou em tradução. 